\title{
A Report of Post-Concussion Syndrome in Post-Moderate Traumatic Brain Injury Patients
}

\author{
Yuanita Eka Maulinda ${ }^{1}$, Endiyono ${ }^{2}$ \\ ${ }^{1,2}$ Department of Health, Universitas Muhammadiyah Purwokerto, Indonesia
}

\begin{tabular}{l} 
ARTICLE INFO \\
\hline Article history: \\
DOI: \\
$\underline{10.30595 / p s h m s . v 2 i .250}$
\end{tabular}

Submitted:

December 6, 2021

Accepted:

January 21, 2022

Published:

January 26, 2022

\section{Keywords:}

Brain injury; accident; PostConcussion Syndrome

\begin{abstract}
Traumatic brain injury is the most common injury, especially in motorcycle riders who do not wear helmets or those who wear unsafe helmets. This injury can be fatal and result in death, but it can also be healed without any sequelae or with varying sequelae. The type of sequelae that commonly occurs after a traumatic brain injury is Post-Concussion Syndrome. Moreover, it has some symptoms such as headaches, impaired concentration, tiredness, anxiousness, dementia, and impaired cognitive function. Based on its onset, Post-Concussion Syndrome is classified into 3: acute (the symptoms appear less than one month after injury), subacute (the symptoms appear from 1 to 12 months), and chronic (the symptoms appear more than a year). The purpose of this research is to provide an overview of symptoms in cases of Post Concussion. Syndrome that occurs after 6 months after moderate head injury. The design of this study used a case report method in order to report cases in detail through interviews and direct observation on respondents. The results of Rivermead, Galveston Orientation and Amnesia Tests conducted 6 months after moderate traumatic brain injury, indicated that respondents experienced PostConcussion Syndrome and Retrograde Amnesia. The conclusion of PostConcussion Syndrome experienced by the respondents was subacute with several symptoms such as headache, dementia, impaired concentration, anxiousness, and memory loss of before injury.
\end{abstract}

This work is licensed under a Creative Commons Attribution 4.0 International License.

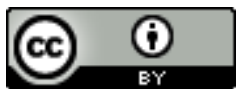

\section{Corresponding Author:}

Endiyono,

Department of Health,Universitas Muhammadiyah Purwokerto,

Soepardjo Rustam Street KM. 7, Banyumas, Indonesia

Email: endiccrnunpad@gmail.com

\section{INTRODUCTION}

Traffic accidents that often occur in Indonesia seem familiar. Traffic accidents most often occur in car and motorcycle drivers. The balance between drivers, increasingly advanced vehicle technology and service providers on the road are the three elements that determine transportation mobility. If one of these aspects does not work properly, there will be a gap that will lead to accidents.[1]

A traffic accident is an incident in road traffic involving at least one vehicle that causes injury, damage and loss to the victim. Traffic accidents can cause physical harm to victims who experience them such as injury, physical disability and even death. Injuries due to traffic accidents often occur in Indonesia, this is the biggest cause of disability and mortality in developing countries.[2]

According to the Indonesian Health Research and Development Agency in 2013, there was an increase in the percentage of injuries in traffic accidents to $8.2 \%$, with the second most common cause of injury being motorcycle accidents $(40.6 \%)$. Based on data on traffic accident victims in the Central Java region, the number of accidents continues to increase every year annually, there were 24,895 fatalities in 2017 and 28,051 fatalities in 2020.

Banyumas Regency is one of the regencies in Central Java province which is located on an inter-city road so that it has a fairly high level of traffic density. This is a major factor in traffic jams and accidents. 
According to data on traffic accident victims in the Banyumas Regency in 2020, traffic accidents in the Banyumas area in 2020 were 1,983 accidents, with 217 deaths, 1 person with serious injury and 1,765 minor injuries.

Head injuries are the most common injuries in traffic accidents, especially for motorcyclists who do not use helmets or use helmets that do not meet established standards [4]. Based on research conducted at Dr. Sardjito Hospital Yogyakarta for the period July - December 2011 reported more than 60\% of patients with head injuries will experience Post Concussion Syndrome. Several factors that can affect the risk of severity of head injury are age, mechanism of injury, initial Glasgow Coma Scale (GCS) score, hypotension, use of alcohol and drugs.[5]

The occurrence of head injuries can include trauma to the brain, skull, and scalp [6]. Head injuries can be fatal such as death but can also heal completely as usual without any residual symptoms or recovering with residual symptoms or what is commonly called Post Concussion Syndrome.

PCS (Post Concussion Syndrome) is a history of head trauma accompanied by symptoms such as loss of consciousness. The onset of symptoms of Post Concussion Syndrome is maximum after 4 weeks accompanied by three or more of the symptoms such as headache, dizziness, malaise, fatigue, intolerance to noise, maladaptive and unstable emotional responses, anxiety, reduced concentration, memory disturbances, insomnia, and hypochondria. [7]

The neurological sequelae that occur in individuals will vary widely. Some of the patients with mild head injury will experience sequelae after the injury. The distribution of sequelae after head injury can result in nearly similar neurologic sequelae in patients of mild, moderate, or severe severity. Cognitive impairment sequelae provide persistent and more severe disability than physical impairment sequelae. The most frequently disturbed cognitive disorders are attention, memory, and executive function.[8]

The decline in cognitive function in the form of memory impairment was greater after mild head injury than after moderate head injury and severe head injury with a percentage of $60 \%$. Concentration difficulties occurred in patients after mild head injury (65\%), after moderate head injury (60\%), and after severe head injury (40\%). Fatigue was complained of $60 \%$ after mild head injury and moderate head injury, as well as $35 \%$ occur in patients after severe head injury. The incidence rate of epilepsy in post-head injury patients is $5.2 \%$. Headache after head injury was $21.2 \%$ and vertigo was $18 \%$.

Individuals who experience post-minor head injury have a higher risk of developing epilepsy than the normal population. Individuals with severe head injury with a GCS score of less than 9 have a greater risk of developing epilepsy. Epilepsy or convulsions can also occur soon after a head injury occurs. The incidence of epilepsy can also occur in the first year with a presentation of about $80 \%$. Sleep disorders that are commonly experienced by patients after a head injury can be insomnia, hypersomnia, and sleep apnea.[8]

Based on its onset, Post Concussion Syndrome is classified into 3, namely acute (symptoms appear less than one month after injury), subacute (symptoms appear 1 to 12 months), and chronic (symptoms appear more than a year) [8]. The variety of sequelae that occur after a head injury is diverse and quite extensive, ranging from very mild which can interfere with daily activities and/or work, to severe sequelae that can be inconvenient for the sufferer because daily activities will be very disturbed and even dependent. with the help of others.

The type of sequelae that occurs after a head injury is called Post Concussion Syndrome or better known as post-head injury syndrome, these symptoms can include several problems such as headache, vertigo,impaired concentration, sleep disorders, easy to feel tired, easily anxious, memory loss, epilepsy, and impaired cognitive function. Each individual does not always have the same symptoms, but the common symptoms that often appear are headaches and memory loss.

The study subject that will be studied is a 19-year-old male teenager with the initials $\mathrm{Mr}$. $\mathrm{N}$, the subject was diagnosed with a moderate head injury after experiencing a traffic accident in 2020. Subjects were known to have sequelae 6 months after head injury through the results of the Rivermead questionnaire. Subjects reported symptoms that appeared in the form of headaches, forgetfulness, difficulty concentrating and restlessness.

\section{METHOD}

The research design used in this case study is a case report or case report. A case report is a case report that is explained in detail starting from signs, symptoms, diagnoses, interventions and evaluations. Case report aims to describe the clinical manifestations, clinical course and prognosis of a case. [8]

This research was conducted in Jipang Village, Karanglewas District. The time needed in this research is May and June 2021 by giving the Glaveston Orientation and Amnesia Test which is carried out once a day for 3 consecutive days.

The subject in this case study was a 19-year-old teenager who reported experiencing symptoms after a head injury, the GCS value when he had a head injury was 10 (delirium) and was included in a moderate 
head injury. In this case study, the research subjects studied had the following inclusion and inclusion criteria:

1. Inclusion criteria

This criterion is a criterion intended for study subjects who are able to represent the sample and have met the requirements as a sample.

a. Respondents with moderate post head injury.

b. Respondents who experienced sequelae after head injury or Post Concussion Syndrome during the first 6 months.

c. Respondents who have a history of previous head injury.

d. Respondents who have been examined through the Rivermead Post Concussion Syndrome Questionnaire and Galveston Orientation and Amnesia Tests.

2. Exclusion criteria

These criteria are respondents who are not used as subjects in this case study, including:

a. Respondents who did not experience Post Concussion Syndrome in the first 6 months after head injury.

The focus of the case study in this scientific paper is to identify symptoms that appear after a head injury in the first 6 months after a head injury.

1) Post ConcussionSyndrome: Rivermead's Indonesian version of the Post Concussion Syndrome Questionnaire.

2) Post Traumatic Amnesia: Sheet interview Orientation Test and amnesia Galveston

3) Level Awareness: Glasgow Coma Scale

\section{RESULTS AND DISCUSSIONS}

3.1.Result

The author conducted research on case reports of Post Concussion Syndrome in patients after moderate head injury in Jipang Village, Karanglewas District through RivermeadPost Concussion Syndrome Questionnaires and Galveston Orientation and Amnesia Tests. The following are the results of this case study:

1. Characteristics of Respondents

Initials Mr. N, 19 years old, male, Islamic religion, last education SMK, respondent's main complaint at the time of injury was loss of consciousness, lesions and bruises on the head, memory loss. The respondent's Glasgow Coma Scale value when injured was 11 (E3M4V4) Delirium, the results of the Rivermead PCS questionnaire respondents experienced headaches, easy to forget, difficult to concentrate and restless. Galveston's Orientation and Amnesia Test score (TOAG) was 90, the respondent had no history of any disease.

The GCS value of 10 in the respondents is included in the moderate head injury. In accordance with the theory, head injuries can be classified based on the severity which is assessed using the Glasgow Coma Scale (GCS). Minor head injuries have a GCS score of 13-15, moderate head injuries have a GCS score of 9-12 and severe head injuries have a GCS $<8$.

The results of the RivermeadPost Concussion Syndrome questionnaire showed that respondents experienced several symptoms such as headaches, difficulty concentrating, forgetfulness and anxiety on a scale of 2 (mild problems). Respondents have never taken medication if the symptoms of PCS above appear because the symptoms can disappear by themselves. Comparison between after and before the accident the respondent never experienced these symptoms before the accident. Respondents had a history of post-KLL disease which resulted in fractures of the toes.

2. Characteristics based on Galveston's Orientation and Amnesia Test (TOAG) scores

Table 1. Galveston'sOrientationand Amnesia Testscores

\begin{tabular}{llll}
\hline Name & Day 1 & Day 2 & Day 3 \\
\hline Tn. N & 75 & 85 & 90 \\
\hline
\end{tabular}

Based on the table 1, the researcher conducted the test 3 times, the first day showed that the respondent could not answer 5 questions so that he got a score of 75 out of 100 , the second day the respondent could not answer 3 questions so he got a score of 85 out of 100, the third day the respondent could not answer 2 questions so he got a score of 90 out of 100, the 2 questions that the

Proceeding homepage: https://conferenceproceedings.ump.ac.id/index.php/pshms/issue/view/10 
respondents could not answer were the same questions since the Galveston Orientation and Amnesia Test was conducted, these 2 questions were also included in the first 5 questions that the respondents could not answer.

\subsection{Discussion}

Based on the results of research that was conducted on Wednesday, May 5, 2021 in Jipang Village RT 03 RW 03, Karanglewas District, it was found that the respondent had a traffic accident in October 2020 at 04.00 WIB, the respondent was taken to the hospital in an unconscious state due to trauma to the head. According to Krisanty Paula's theory, et al. (2013) [9], respondents experienced deceleration injuries. This is because the head hits or strikes a stationary object, for example when a fall or traffic accident can cause a collision between the head and a stationary object that is hit.

This study reports the incidence of Post Concussion Syndrome in patients 6 months after moderate head injury. Sources of data used are primary data taken through direct observation and interviews with respondents. The data collection procedure that has been carried out by the researcher is starting by looking for respondents who match the inclusion criteria that have been set. Then contact the respondent and make a contract to meet in person. After the respondent agreed, then the researcher came to meet the respondent, introduced himself, explained the purpose and objectives of the study, the research procedure, the benefits of the research and submitted informed consent to the respondent.

After the respondent signed the informed consent given and said he understood about the research to be carried out, the researcher then made observations by examining the identity, chief complaint and disease history. Then the researcher gave a Rivermead questionnaire to find out whether the respondent had residual symptoms after 6 months after a head injury, the Rivermead examination was an examination in the form of filling out a questionnaire to find out what symptoms the patient experienced after a head injury.

Post Concussion Syndrome or post head injury syndrome is a collection of advanced symptoms or sequelae after mild, moderate or severe head injuries which include somatic, cognitive and psychosocial symptoms. Generally the symptoms that appear can be headaches, vertigo, epilepsy, cognitive disorders and sleep disorders. [10] who said that headache was the most common complaint after a head injury with a percentage of $21.2 \%$. Headache experienced by respondents is a clinical symptom in the form of somatic deficits, usually patients with Post Concussion Syndrome complain of headaches that feel longer and more frequent than before the injury.

In addition to somatic deficits, respondents also experienced psychological and cognitive deficits. The psychological deficit experienced by respondents is anxiety, this is in accordance with the journal written by Kaury S and Benavides R. [11] which explained that post-head injury patients will often experience psychological disorders such as PTSD (Post Traumatic Stress Disorder) and anxiety due to chronic pain he experienced after the head injury. Cognitive deficits that occur in respondents are easy to forget and difficult to concentrate.

Symptoms that appear can be different for each person because the symptoms that appear are only subjective complaints. In the article 'Post Concussion Syndrome,' Lishman (1988) proposed that neurobiological and psychological factors play an important role in the early symptoms of Post Concussion Syndrome. [12] Respondents experienced symptoms in the form of headaches, forgetfulness, difficulty concentrating, and restlessness.

Furthermore, the researchers conducted interviews using the Galveston Orientation and Amnesia Test observation sheet, this examination was carried out to determine the presence of orientation disorders and amnesia in post-head injury patients. This examination is still the most frequently used examination, the technique is by giving 10 questions that can measure the level of orientation, attention and memory.

Galveston's Orientation and Amnesia tests were carried out for 3 consecutive days. The first day showed that the respondent could not answer 5 questions so that he got a score of 75 out of 100, the second day the respondent could not answer 3 questions so that he got a score of 85 , the third day the respondent could not answer 2 questions so he got a score of 90 .

The question that cannot be answered by the respondent is how did the respondent get to the hospital during the accident and can the respondent describe the last memory event before the accident. Respondents said they could not remember some events and events in the past before the accident. This shows that the respondent has posttraumatic amnesia with retrograde type. This is in accordance with the theory put forward by Rindayu. [13] retrograde amnesia is a disorder in the ability to remember past events and previously known information. This amnesia is one of the most well-known types of amnesia. People affected by this type of amnesia have difficulty and inability to remember the past before the amnesia started.

Respondents were able to answer questions about events that were remembered after an injury, therefore respondents were not included in the criteria for patients with anterograde amnesia because according to Ridayu. [13] Anterograde amnesia is a disorder of the ability to learn new information. 
Anterograde amnesia is the opposite of retrograde amnesia. People affected by this type have problems and an inability to make and form new memories. They can easily forget events that happened, names or faces of people they just met but memories from the past can be easily recalled by them. Anterograde memory is usually the last function that returns after the patient returns to consciousness after the trauma.

Respondents do not have a history of diseases that can trigger a poor prognosis of symptoms of Post Concussion Syndrome. In accordance with the theory of Broshek, et al which states that the poor prognosis of Post Concussion symptoms. [14]

Syndrome is a patient who has a history of previous psychological disorders. Conversely, good prognostic factors are those who do not have a comorbid psychological disorder and those who are able to accept their "new condition" well.

Respondents experienced symptoms of Post Concussion Syndrome in the form of headaches, difficulty concentrating, often forgetting and anxiety on a scale of 2 (mild problems) which can be overcome with rest. Respondents also experienced Post Traumatic Amnesia with retrograde symptoms marked by the results of the Galveston Orientation and Amnesia Test which were carried out for 3 consecutive days where the respondent could not answer questions about how he got to the hospital and could he explain the last event he could remember before the accident. Respondents seemed to be able to adapt to their new conditions well and were able to carry out their activities as before.

\section{CONCLUSIONS}

Based on the evaluation of the results of the case study on the incidence of Post Concussion Syndrome in moderate head injury patients in respondents who have experienced moderate head injuries, it can be concluded as follows:

1. Post Concussion Syndrome can occur in patients after moderate head injury after 6 months as indicated by the results of Rivermead'sPost Concussion Syndrome questionnaire and Galveston's Orientation and Amnesia Test showing symptoms that appear in the form of headache, forgetfulness, difficulty concentrating and restlessness.

2. Respondents experience symptoms of Post Concussion Syndrome with mild intensity problems that can be overcome by rest, the symptoms are headache, forgetfulness, difficulty concentrating and restlessness.

3. Based on the results of the Galveston Orientation and Amnesia Test which was carried out for 3 consecutive days, respondents experienced an increase in remembering events or events after an accident from a score of 75 to 90 . A score of 90 was obtained because the respondent could not answer 2 questions from the given test, the questions that could not be answered were how he got to the hospital and could he explain the last event that he could remember before the accident.

\section{Acknowledgements}

Thank you to Allah SWT, both parents and all comrades in arms who have helped from beginning to end.

\section{REFERENCES}

[1] Z. Denianto, "Sistem Informasi Kecelakaan lalu lintas jalan raya di kabupaten banyumas [skripsi]," Yogyakarta: Teknik Informatika Fakultas Teknologi Industri, Universitas Islam Indonesia, 2019.

[2] M. I. Arrasyid, "Gambaran Korban Meninggal Dunia Dengan Cedera Kepala Pada Kecelakaan Lalu Lintas Di Bagian Forensik Rsup Dr. M. Djamil Padang Tahun 2018-2019 [skripsi],” Padang: Fakultas kedokteran, Universitas Andalas, 2020.

[3] WHO, "World Health Organization. Road Traffic Injuries,” 2017.

[4] J. Jiang, "Head Trauma in China. Injury," Int. J. Care Injured 44, 2013, 1453-1457.

[5] P. Morton, et al, "Keperawatan Kritis Volume 2 Pendekatan Asuhan Holistik," Jakarta : EGC, 2012.

[6] M. Latief, W. Manusubroto, "Faktor Resiko Terjadinya PostConcussionSyndrome Pada Pasien Cedera Kepala Ringan Di Rumah Sakit Umum Pusat Dr. Sardjito Yogyakarta Evaluasi Satu Tahun Pasca Trauma (Penelitian Lanjutan)," Yogyakarta: Ilmu Bedah, Universitas Gadjah Mada, 2013.

[7] P.G. Sudira, et al, "Insidensi Post Concussion Syndrome Dan Sekuel Neurologis Pada Pasien 
Cedera Kepala Di RSUP Dr Sardjito Januari - Juni 2012,’Yogyakarta, 2014.

[8] B. Murti, "Desain Studi," Surakarta: Fakultas Ilmu Kedokteran Universitas Sebelas Maret, 2013.

[9] Krisanty Paula, et al., “Asuhan Keperawatan Gawat Darurat,” Jakarta: Trans Info Media, 2013.

[10] M.S., Greenberg, "Handbook of Neurosurgery 5th ed," New York: Thieme Medical Publisher, 2019.

[11] S. Kaury, R. Benavides, Paint With Traumatic Brain Injury and Psycological Disorders. Journal of Progress in Neuropsychopharmacology \& Biological Psychiatry, 2017.

[12] N.D Silverberg, G.L. Iverson, "Etiology Of The Post-Concussion Syndrome: Physiogenesis And Psychogenesis Revisited," Maryland: NIH Publication, 2011.

[13] A.F. Rindayu, "Amnesia Experienced By The Main Character Cal Armistead's Being Henry David" Novel. Malang: Maulana Malik Ibrahim State Islamic Universityof Malang, 2017.

[14] D.K. Broshek, A.P. De Marco, J.R. Freeman J.R., “A Review Of Post- Concussion Syndrome And Psychological Factors Associated With Concussion, Brain Inj, 29(2):228-237, 2015. 